\title{
Filosofía de la sinonimia en la España de las Luces*
}

FRANÇOISE ETIENVRE

Universidad de Caen

S'il y avait des synonymes parfaits, il y aurait deux langues dans une même langue. Quand on a trouvé le signe exact d'une idée, on n'en cherche pas d'autre.

Du Marsais, Des Tropes (III, 12)

Si bien los retóricos de la Antigüedad, de la Edad Media y del Renacimiento no dejaron de observar los matices que permiten distinguir entre sí palabras aparentemente equivalentes, les corresponde a unos cuantos autores del siglo XVIII la primacía de un planteamiento teórico del problema de los sinónimos. ¿Cómo explicar, efectivamente, que

* Este trabajo es la versión ampliada de una ponencia presentada en el Circolo Filologico Linguistico Padovano (Dir.: Gianfranco Folena), el 2 de marzo de 1983. 
en una misma lengua coexistan varias palabras para expresar una misma idea? A esta pregunta, que nace de un análisis cada vez más riguroso y complejo de la lengua y, en particular, de la significación lingüística, el primero en contestar es el abate Girard, con su libro La Justesse de la langue françoise, que publica en 1718 y del cual presenta, en 1736, una versión refundida y muy ampliada, bajo la forma de un verdadero tratado de sinónimos ${ }^{1}$.

El criterio de diferenciación entre las palabras sinónimas propuesto por Girard se funda en la necesaria distinción de una idea principal y de varias ideas accesorias en el significado de cada una de dichas palabras. Esta teoría orienta toda la reflexión del siglo ilustrado acerca de la sinonimia, tanto en Francia -donde está desarrollada principalmente por Du Marsais, Beauzée, Diderot y d'Alembert- como en los demás países europeos.

Estudiar la participación de España en esta reflexión general no es aventurarse por terra incognita, puesto que Fernando Lázaro Carreter nos ha proporcionado unas informaciones esenciales en un libro pionero que, desgraciadamente, no parece haber tenido entre los dieciochistas el éxito y la difusión que merecía ${ }^{2}$. Aquí, por cierto, he de seguir un camino tan magistralmente abierto, ensanchando o modificando un tanto su trazado, en determinados casos.

\section{Indiferencia y ciencia confusa}

Es de advertir, desde un principio, que la exịstencia de sinónimos tarda mucho tiempo en ser considerada como un problema por los eruditos españoles del siglo XVIII, y en vano se buscaría la más mínima alusión a este tema durante la primera mitad de la centuria. Feijoo, por

1 Synonymes françois, leurs significations et le choix qu'il en faut faire pour parler avec justesse, París, Impr. de la $\mathrm{V}^{\text {ve }} \mathrm{d}$ 'Houry, 1736 (hubo numerosas reediciones a lo largo del siglo XVIII).

2 Las ideas lingüísticas en España durante el siglo XVIII, Madrid, CSIC, 1949, pp. 78-87. En el presente artículo no se estudia, por supuesto, todo lo que se escribió sobre los sinónimos durante la centuria ilustrada en España: quedan fuera de mi encuesta, entre otras, las consideraciones de Vargas Ponce (en su Declamación contra los abusos introducidos en el castellano [1791], citada por Lázaro Carreter, p. 82), así como las adiciones de Munárriz a su traducción de las Lecciones sobre la retórica y las bellas letras de Hugo Blair (1798) y las observaciones de Alvarez Cienfuegos (1799, mss. de la Biblioteca Nacional y de la Real Academia Española). No me ha sido posible consultar la tesis doctoral inédita de Marie-Elisabeth Metzger, Estudios sobre los diccionarios de sinonimos castellanos (Univ. de Madrid, 1954). 
ejemplo, al examinar las principales virtudes de una lengua, pondera la «copia de voces» del castellano, el cual le parece superior, desde este punto de vista, al idioma francés. Pero no repara el sabio benedictino en los inconvenientes que representa, con respecto a lo que él mismo llama la «propriedad del estilo», el uso indiferente de varias palabras, consideradas como equivalentes, para significar un concepto único ${ }^{3}$. El mismo criterio cuantitativo lo utiliza también Mayans, en una perspectiva muy parecida a la de Feijoo, cuando declara, en un texto contemporáneo del Theatro crítico universal, lo siguiente:

Con razón me duelo de que en el arte de decir no procuremos, no sólo igualar, sino también exceder a las demás naciones, y más siendo tan notoria la ventaja que nuestro lenguaje hace a los extraños. Tenemos una lengua expresiva, en extremo grave, majestuosa, suavísima y sumamente copiosa ${ }^{4}$.

Por otra parte, se observa que en su Rhetórica, obra posterior en más de treinta años a este texto, el erudito valenciano, al tratar de la «claridad de la elocución», de las «figuras de amplificación» o del «exceso de palabras» ${ }^{5}$, ni siquiera menciona los sinónimos: éstos, por lo tanto, no parecen existir a sus ojos como materia de estudio, y menos aún como problema.

Sin embargo, algunos años antes, exactamente en 1751, Ignacio de Luzán había revelado a sus compatriotas, en sus famosas y muy leídas Memorias literarias de París, el éxito encontrado por la obra de Girard. En su comentario a la misma, había expresado un saludable deseo:

Este asunto es imitable, y sería útil en todas las lenguas. Yo quisiera que en España algún erudito bien versado en los buenos autores, y en el mejor uso, y en la verdadera propia significación de las voces, se dedicase seriamente a enseñarnos con precisión la diferencia que hay entre las voces que se tienen por sinónimos ${ }^{6}$.

Es muy probable, como lo sugiere Lázaro Carreter, que estas líneas de Luzán no sean del todo ajenas a la publicación, en 1756, de un librito titulado Ensayo de los synónimos. Pero el autor de este ensayo

3 Véase, en el Theatro crítico universal, tomo I (1726), el «Paralelo de las lenguas castellana y francesa» ( $\$ 4$ y 5 ).

4 Oración que exorta a seguir la verdadera idea de la eloquencia española, (s. $1 .$, Cosmópolis), 1727. Cito por la ed. de Lyon, Deville Hermanos, 1783, p. 142 (en la cual esta Oración viene después de las Cartas de Don Nicolás Antonio y de Don Antonio de Solís, editadas por el mismo Mayans). Este texto, como todos los que se citan en este trabajo, está reproducido aquí con grafía y puntuación modernas.

5 Rhetórica, Valencia, Herederos de Gerónimo Conejos, 1757, tomo II, libro tercero, capítulos X, XII y*XIII.

6 Citado por Lázaro Carreter, op. cit., p. 79. 
-un tal Manuel Dendo y Avila, desconocido en la República de las Letras- no tenía seguramente ni las dotes ni el saber que requería tan delicado tema. Dicho librito consta de una breve introducción y de trece artículos, dedicados, cada uno, al examen de dos voces consideradas como sinónimas. La introducción no ofrece, a pesar de exigirlo la novedad del asunto, una clara exposición del problema de la sinonimia: es más bien una serie de apreciaciones, muchas veces mal conectadas y entremezcladas con ejemplos no siempre convincentes, que no compensan en absoluto la ausencia de criterio fijo. Si consigue el lector superar esta primera impresión, desde luego poco favorable, puede sin embargo entresacar de estas páginas preliminares algunas observaciones no desprovistas de interés.

Así, por ejemplo, una declaración inicial sobre el mejor método para determinar el valor exacto de las voces. Escribe el atrevido Dendo:

Creo que las reflexiones sobre el uso de las voces son las únicas que pueden abrir la senda para el conocimiento de su valor, y para usar de ellas oportunamente, buscarlo en los libros de elocuencia, y consultar a los maestros de la lengua española, sería un malogrado afán, que vertiese [sic] sobre nuestra duda nuevas confusiones: los hombres eruditos no han cuidado de hacer diferencia alguna entre las voces que hoy se tienen por sinónimas, antes las han tomado indiferentemente.

$\mathrm{Y}$ añade a continuación (al principio del párrafo siguiente):

El uso es el que da a las voces, en los idiomas vivos, todo el precio y fuerza que tienen, es capaz de alterar las significaciones y mudarlas ${ }^{7}$.

Al negar a los tratados de retórica y a los mejores autores cualquier autoridad para servir de guía o de referencia, Dendo va en contra de los consejos de Luzán y toma el riesgo de chocar con la mayoría de los eruditos españoles, no formando parte además de ese culto gremio. Resulta demasiado evidente el carácter excesivo de tan perentoria afirmación para que se insista en él. Pero, a pesar de su torpeza, esta declaración tiene por lo menos el mérito de llamar la atención sobre un factor primordial en materia de lengua en general, y de sinonimia en particular: el uso, ce tyran des langues, según Du Marsais ${ }^{8}$. De paso, Dendo indica luego que toma la palabra «uso» en el sentido de «uso común»; pero, fuera de ese calificativo, no nos proporciona desgraciadamente

7 Manuel Dendo y Avila, Ensayo de los synónimos, Madrid, Antonio Muñoz del Valle, 1756, pp. 2 y 3.

8 César Chesneau Du Marsais, Des Tropes, ou des diférens sens dans lesquels on peut prendre un même mot dans une même langue [...], París, Vve J. B. Brocas, 1730, capítulo IIl, 12 (p. 246 en la ed. de 1977, Paris, Le Nouveau Commerce). 
ninguna aclaración complementaria sobre una noción tan importante $y$, como lo veremos, tan difícil de definir.

Intenta, en cambio, explicar el método que permite establecer diferencias entre los sinónimos, afirmando que la única regla posible es "comparar las sensaciones e ideas que se excitan de los sinónimos, en la primera aprehensión de ellos y en sus combinaciones con otras voces, para deducir la diferencia y fijar su significación $)^{9}$. El contenido de esta frase incita a interrogarse sobre el conocimiento que tendría Dendo de la teoría de Girard, puesto que no aparece ahí ninguno de los principios claves establecidos por el autor francés, ni siquiera la ya famosa distinción entre idea común o principal e idea accesoria. Lo cierto es que nuestro ensayista no se refiere explícitamente a ninguna obra, no menciona a ningún autor. $Y$, cualquiera que sea el punto de partida de su singular trabajo, manifiesta, por lo confuso de esta aseveración y de algunas otras formuladas de la misma manera, que dista mucho de dominar la nueva doctrina que pretende asentar entre sus compatriotas.

En la introducción se evocan también, naturalmente, los beneficios que resultarían de un esfuerzo general por deslindar los respectivos significados y usos de las palabras que suelen admitirse como sinónimas:

[...] Una vez conocida la significación de las voces, se usaria de ellas con precisión, y correctamente; pero no consistiría en esto el principal fruto, sino en que tratándose de averiguar la verdadera significación de los sinónimos, procurarían todos los que se precian de literatos instruirse mejor en la Lógica; porque en este caso sería notable la mala aplicación de cualquiera voz, que tiene su significado fijo; no se gastarían en las cláusulas voces superfluas, ni se asignarían términos para significar una cosa simple; no se hicieran combinaciones de sílabas para decir lo que otros dicen con una sola; no trabajarían en buscar abundancia de palabras, ni ordenar frases, creyendo que apuran con ellas la elegancia de la lengua, que corrompen; pero si después de fijado el valor de las voces se usase de ellas oportunamente, en el caso que las multiplicasen, nos darían en cada una un nuevo concepto ${ }^{10}$.

Este argumento, fundamental en la nueva perspectiva que Dendo intenta adoptar, les parecería totalmente insólito y hasta provocativo a los lectores de este Ensayo de los sinónimos, ya que nadie hasta la fecha, en España por lo menos, había puesto en tela de juicio el mérito estilístico de la tan celebrada copia verborum.

Las contadas consideraciones que merecen destacarse en la intro-

9 Dendo y Avila, op. cit., p. 5.

10 Ibíd., pp. 9-10. 
ducción no deben hacer olvidar que no son más que «algunos rayos de luz» - según la expresión de un sinonimista posterior ${ }^{11}$ - en un conjunto generalmente oscuro y desordenado. Se nota, en efecto, en la parte ilustrativa del Ensayo, la misma incapacidad para un razonamiento claro y preciso. En no pocos casos, el lector se pierde con su guía por los meandros de un enmarañado examen de determinadas voces. Abundan los ejemplos sacados del «uso común», pero esta documentación resulta vana, muy a menudo, porque desemboca en unas conclusiones discutibles, o incluso francamente erróneas. Además, ¿cómo admitir que se estudien en un tratado de sinónimos palabras que no pueden verdaderamente considerarse como tales (por ejemplo, «ver y mirar» $\mathrm{u}$ «oler y heder»), aunque lo reconozca in fine el autor? Para disculpar las insuficiencias de su libro, Dendo dice «haber tomado sólo casualmente y por divertimiento este asunto ${ }^{12}$; pero, como bien lo había advertido Luzán, dicho asunto requería buena erudición y dedicación seria.

La presencia de defectos tan evidentes en este Ensayo hubiera justificado y necesitado unas reacciones algo severas; mas su publicación parece no haber suscitado ni elogios, ni censuras entre los contemporáneos ${ }^{13}$. Este silencio refleja probablemente una marcada indiferencia, motivada por la mediocridad de la obra y, tal vez, por el cortísimo número de lectores dispuestos a tomar en consideración el problema planteado.

\section{El poeta y los sinónimos}

El poco interés que despierta al sur del Pirineo la sinonimia à la française está comprobado por la imposibilidad de encontrar bajo la pluma de autores españoles, durante muchos años después del malogrado intento de Dendo y Avila, la menor huella de esta nueva teoría. De esta indiferencia, por no decir resistencia u hostilidad, encontramos una buena ilustración en un manuscrito de Tomás de Iriarte, titulado

11 Santiago Jonama, Ensayo sobre la distinción de los sinónimos de la lengua castellana, Madrid, Impr. Real, 1806, p. XI del Prólogo.

12 Dendo y Avila, op. cit., p. 12.

13 Hay que esperar al año de 1800 para que se publique, en el Mercurio de España, un comentario del Ensayo de Dendo y Avila: se trata de una crítica muy severa cuya tonalidad se percibe claramente en la apreciación final: «Es preciso confesar que el Ensayo de los sinónimos de Dendo es una obra mala, y no perdería nada la verdad si añadimos que es malísima» (citado por Bernard Lévy, "Libros de sinonimia española», Hispanic Review, X, 1942, p. 288). 
Diccionario de sinónimos y equivalentes ${ }^{14}$. En las quince hojas autógrafas de que consta este manuscrito, las ocho primeras corresponden a una exposición de la «idea» del Diccionario, y me ha parecido oportuno reproducirlas íntegramente al final del presente trabajo. Las siete restantes reúnen, por una parte, los borradores de las hojas anteriores y, por otra parte, una lista de Frases y refranes, con unas pocas Voces latinas. Esa lista, por limitarse a la letra $a$ y carecer de comentario, no merece la misma atención que la introducción al Diccionario. El manuscrito viene sin fecha, pero la alusión que hace Iriarte al tomo primero del Diccionario de la Real Academia Española, «últimamente corregido y aumentado» ${ }^{15}$, permite considerar con seguridad el año de 1770 como terminus a quo para la redacción de estas hojas, autorizando el adverbio «últimamente» para pensar que no serán muy posteriores a 1775. No es inútil observar que tiene unos veinte años el autor de este proyecto, y que - ¿desgraciadamente? - no había de realizarlo.

Las ocho primeras hojas del manuscrito sirven, pues, para dar, a través de varias advertencias, una «idea» de la obra, de su concepción y objeto, así como de la posición del joven poeta confrontado con el problema de los sinónimos. Con este nuevo léxico («vocabulario» o «tesoro», como él mismo lo llama), Iriarte desea alcanzar un determinado público, con una finalidad práctica, como lo declara una enmienda al larguísimo título, tal como puede leerse en el manuscrito: Prontuario útil [en vez de Obra, palabra tachada] para los que desean escribir con propiedad y elegancia en prosa y verso ${ }^{16}$. No se trata, por tanto, de un diccionario cualquiera, sino de un instrumento de trabajo para cuantos quieran usar decentemente de su pluma. Iriarte, con ese afán pedagógico que le caracteriza, insiste en esta finalidad de su futuro libro, repitiendo varias veces que está destinado a los que dominan ya la lengua castellana, «para que los escritores que ya la poseen y se hallan impuestos en los precisos elementos gramaticales tengan un repertorio manual que les subministre prontamente y con abundancia términos en que elegir para expresar sus ideas» (fol. $5 \mathrm{v}$.).

Esta frase, además de explicitar la utilidad del Prontuario, define implícitamente los sinónimos, presentándolos en estrecha relación con la noción de «abundancia». Este criterio tradicional, lo plasma muy bien Iriarte en la primera advertencia, cuando afirma que existe en cas-

14 Manuscrito mencionado y presentado por primera vez en Lázaro Carreter, op. cit., pp. 80-81, donde están reproducidas unas cuantas frases.

15 Fol. 8 r. (veáse nota 59).

16 Véase infra, nota 52. 
tellano «una copiosa porción [de sinónimos], sin embargo de la opinión que pretende no haberlos verdaderos y legítimos en ningún idioma. Tales son, por ejemplo, asno, burro, borrico y jumento; partera y comadre; guitarra y vihuela; cerdo, puerco, cochino y marrano; motín, tumulto, sedición y levantamiento, etc., entre cuyas voces y otras semejantes no puede hallar diferencias el discernimiento más sutil, pues expresan la propia idea o cosa en todas ocasiones y respectos» (fol. 2 v.). No puede imaginarse más clara negación de la existencia de diferencias semánticas entre las palabras sinónimas, cuya abundancia —según dice, desde un principio, Iriarte- «demuestra la fecundidad de nuestra lengua» (ibíd.). Y, al afirmar esto, repite el fabulista la celebración de la lengua nacional, indudablemente más rica que las demás.

Pero no debe pasar inadvertida la alusión a «la opinión» según la cual no hay sinónimos «verdaderos y legítimos» en ningún idioma. Esa «opinión» es, por supuesto, la de Girard y de sus secuaces, franceses y extranjeros ${ }^{17}$, cuya teoría tal vez está aquí rechazada de modo tan terminante porque ya no deja del todo indiferentes a los ilustrados españoles. El mismo Iriarte, por cierto, no se muestra siempre tan categórico en sus afirmaciones. Si pone tanto ahínco en reservar este Diccionario a los hombres cultos, es seguramente porque tiene clara conciencia de que «la misma abundancia de las palabras sinónimas y casi sinónimas o equivalentes [...] podrá ocasionar gravísimos abusos en la propiedad del estilo» (fol. $8 \mathrm{v}$.): declaración que matiza considerablemente, $\mathrm{y}$ hasta contradice lo anteriormente citado.

Por otra parte, es de notar que el título primitivamente imaginado no era Diccionario de sinónimos y equivalentes, sino simplemente Diccionario de equivalentes ${ }^{18}$. Puede verse en ello una concesión a la moda, puesto que el término añadido remite a una noción debatida; pero la evolución del título puede también significar que si Iriarte, con esta adición, reafirma la existencia de verdaderos sinónimos, establece sin embargo una distinción entre éstos y los términos que denomina «equivalentes» (es decir, de sentido semejante pero no idéntico). Además, si se exceptúa la primera advertencia, ya citada, se observa que la gran mayoría de los ejemplos aducidos están presentados por el autor, no como «sinónimos», sino como «equivalentes». Y, cuando confiesa -no en las hojas que pueden considerarse como definitivas, sino en el

17 Se conocen adaptaciones de los Synonymes françois al alemán (1758), al italiano (1772) y al inglés (1776).

18 El título que aparece en el borrador (fol. 10 r.) es exactamente: Diccionario poético de equivalentes, pero el adjetivo poético está tachado. 
borrador - que, en realidad, «los legítimos sinónimos son poquísimos» (fol. 10 r., cuarta advertencia), revela que la teoría que sigue rechazando rotundamente ha hecho mella, a pesar de todo, en sus convicciones.

\section{Teoría, plagio y práctica}

La vigencia de la concepción tradicional de los sinónimos, defendida mal que bien por Iriarte en su proyecto manuscrito, no impide sin embargo los progresos de una opinión más crítica. Esta nueva opinión encuentra su mejor portavoz en Antonio de Capmany, quien, por primera vez en España, formula de manera clara el problema teórico planteado por la sinonimia.

Este problema está examinado en su Filosofía de la eloqüencia (1777), en un capítulo titulado «Propiedad de la dicción» ${ }^{19}$. Pero la excelencia de los principios ahí expuestos y la calidad del razonamiento no han de atribuirse a Capmany, sino a Girard y a Beauzée, como lo revela, sin dejar lugar a duda, una confrontación de los textos. Los cinco primeros párrafos de dicho capítulo son efectivamente, con excepción del segundo, una traducción (no declarada) de las dos primeras páginas del interesante prefacio de Beauzée a su reedición de los Synonymes françois de Girard ${ }^{20}$. En cuanto al apartado dedicado precisamente al estudio de los «Términos sinónimos», podrá juzgarse por el cotejo siguiente:

Antonio de CAPMANY, Filosofía de la eloqüencia (1777), páginas 48-50.

(Entre corchetes, las adiciones de Capmany. No se reproduce aquí el primer párrafo, que sirve de transición y parece ser original.)
Abbé Gabriel GIRARD, Synonymes françois, prefacio a la tercera edición (1740), reproducido por Nicolas BEAUZEE, en su reedición de 1769 , págs. VIII-XII.

(Entre corchetes, lo omitido por Capmany.)

19 Filosofia de la eloqüencia, Madrid, Antonio de Sancha, 1777, art. IV, pp. 48-51. Es de notar que esta obra de Capmany no está registrada, entre las que tratan de los sinónimos, por La Viñaza, Biblioteca histórica de la filología castellana, Madrid, Manuel Tello, 1893, tomo III, libro tercero, tercera parte.

20 Synonymes françois [...] par M. l'Abbé Girard [...]. Nouvelle édition considérablement augmentée [...] par M. Beauzée, París, Le Breton, 1769, 2 vols. El prefacio redactado por Beauzée encabeza el tomo segundo. Esta «nueva edición» fue seguida por otras muchas, cada vez más ampliadas, hasta finales del siglo XVIII. 
La delicada diferencia que se halla entre los sinónimos, esto es, el carácter particular de estas voces que se asemejan como hermanas por una idea general y común a todas, las distingue una de otra por alguna idea accesoria y particular a cada una de ellas. De aquí viene la necesidad de elegirlas con acierto e inteligencia, colocándolas oportunamente para hablar con toda exactitud: calidad tan rara como preciosa en un escritor que quiere hacer sólido lo que en otros sólo es brillante.

Esta feliz elección, totalmente opuesta a la vana verbosidad, enseña a decir siempre cosas; enemiga del abuso de las palabras, hace el lenguaje inteligible; juiciosa en el uso de los términos, castiga y fortifica la expresión; rigurosamente exacta, destierra las imágenes vagas y generales, y todos estos correctivos indefinidos [como casi, a modo de, a poca diferencia,] con que se contentan los entendimientos perezosos y superficiales.

En fin, es forzoso decir que el espiritu de discernimiento y exactitud es la verdadera luz que en un discurso distingue el hombre sabio del hombre vulgar.

Para adquirir esta exactitud, el escritor elocuente debe ser algo escrupuloso en las palabras, hasta llegar a conocer que las que se llaman sinónimos no lo son con todo el rigor de una semejanza tan perfecta que su sentido sea en todas uniforme; pues, examinándolas de cerca, se echa de ver luego que esta semejanza no abraza toda la extensión y fuerza de su significado; que sólo consiste en una idea principal que todas incluyen indefinida y generalmente, pero que cada una diversifica a su modo por medio de una idea secundaria o accesoria, que constituye su carácter proprio y particular. [¿Quién dirá que las palabras excitar, incitar, provocar, se pueden usar indistintamente para una misma idea? Lo mismo digo de estotras: miedo, temor, timidez; lo mismo de espantoso, asombroso, horroroso.]
[...] la délicate différence des synonymes, c'est à dire le caractère singulier de ces mots qui, se ressemblant comme frères par una idée commune, sont néanmoins distingués l'un de l'autre par quelqu'idée accessoire et particulière à chacun d'eux: d'où naît, dans beaucoup d'occasions, une nécessité de choix, pour les placer à propos et parler avec justesse; qualité aussi rare qu'aimable, dont le goût est capable de faire briller le vrai et de donner de la solidité au brillant. Tout à fait éloignée du verbiage, elle apprend à dire des choses; ennemie de l'abus des termes, elle rend le langage intelligible; judicieuse dans l'emploi des mots, elle met du fin et même de l'éloquence dans l'expression; exacte, elle bannit les images vagues, et tous les $\grave{a}$-peu-près, dont les esprits superficiels et paresseux se contentent dans leur façon de concevoir comme dans celle de s'expliquer; [antagoniste du confus, elle empêche de s'égarer dans l'étude des sciences.] Enfin, j'ose le dire, l'esprit de justesse et de distinction est partout la vraie lumière qui éclaire et, dans le discours, il est le trait qui distingue l'homme délicat de l'homme vulgaire.

Pour acquérir de la justesse, il faut se rendre un peu difficile sur les mots et ne point imaginer que ceux qu'on nomme synonymes le soient dans toute la rigueur d'une ressemblance parfaite, en sorte que le sens soit aussi uniforme entre eux [que l'est la saveur entre les gouttes d'eau d'une même source.] Car, en les considérant de près, on verra que cette ressemblance n'embrasse pas toute l'étendue et la force de la signification; qu'elle ne consiste que dans une idée principale, que tous énoncent, mais que chacun diversifie à sa manière par une idée accessoire qui lui constitue un caractère propre et singulier. [La ressemblance que produit l'idée générale fait donc les mots synonymes; et la différence qui vient de l'idée particulière qui accompagne la générale fait qu'ils ne le sont pas parfaitement et qu'on les dis- 
Por cierta idea mal entendida de riqueza caen muchos en esta pródiga ostentación de palabras. [Otras veces la incertidumbre $\mathrm{e}$ indecisión que padecen sobre el valor específico y propriedad de ellas les obliga a multiplicarlas para poder hallar entre muchas la que buscan.] A la primera causa digo que no es el valor numeral de las voces el que enriquece el lenguaje, sino el que nace de su diversidad, como la que brilla en las obras de la naturaleza; [y a la segunda añado que el que habla o escribe no tiene aquel pulso cierto y fino que pide el rigor filosófico de la elocución.]

Cuando las palabras varían sólo por los sonidos, y no por la mayor o menor energía, extensión, precisión o simplicidad que las ideas tienen, en lugar de hacer rico al discurso, más le empobrecen, fatigando la memoria. Esto es confundir la abundancia con la superfluidad y hacer, como quien dice, consistir la magnificencia de un banquete en el número de los platos, y no de los manjares $[\ldots]$. tingue comme les diverses nuances d'une même couleur.

Je ne disconviens pas qu'il n'y ait des occasions où il soit assez indifférent de choisir; mais je soutiens qu'il y en a plus où ils ne doivent ni ne peuvent figurer l'un pour l'autre, surtout dans les ouvrages médités et composés avec réflexion. S'il n'est question que d'un habit jaune, on peut prendre le souci ou la jonquille; mais s'il faut assortir, on est obligé à consulter la nuance. Eh! quand est-ce que l'esprit n'est pas dans le cas de l'assortiment? Cela est rare, puisque c'est en quoi consiste l'art d'écrire.]

Qu'une fausse idée de richesse ne vienne pas ici pour fronder mon système sur la différence des synonymes, faire parade de la pluralité et de l'abondance. J'avoue que la pluralité des mots fait la richesse des langues; mais ce n'est pas la pluralité purement numérale, [elle n'est bonne qu'à remplir les coffres d'un avare;] c'est celle qui vient de la diversité, telle qu'elle brille dans les productions de la nature. [La satisfaction de l'esprit, et non le chatouillement de l'oreille, fait l'objet de la conversation et de la lecture; je ne fais donc cas de la quantité des mots que par celle de leurs valeurs.] S'ils ne sont variés que par les sons, et non par le plus ou le moins d'énergie, d'étendue, de précision, de composition ou de simplicité que les idées peuvent avoir, ils me paroissent plus propres à fatiguer la mémoire qu'à enrichir et faciliter l'art de la parole. [Protéger le nombre des mots sans égard au sens,] c'est, me semble, confondre l'abondance avec la superfluité. Je ne saurais mieux comparer un tel goût qu'à celui d'un maître d'hôtel qui feroit consister la magnificence du festin dans le nombre des plats, plutôt que dans celui des mets. [Qu'importe d'avoir plusieurs termes pour une seule idée? N'est-il pas plus avantageux d'en avoir pour toutes celles qu'on souhaite d'exprimer?] 
El último párrafo citado de Capmany termina con una sentencia directamente inspirada en La Bruyère: «[...] Entre las diferentes palabras que pueden hacernos sensible un pensamiento, sólo una es la propria» ( $c f$. «Entre toutes les différentes expressions qui peuvent rendre une seule de nos pensées, il n'y en a qu'une qui soit la bonne», Des Ouvrages de l'Esprit). Cabe advertir que dicha sentencia está reproducida por Beauzée, en el citado prefacio a su reedición del tratado de Girard (tomo II, págs. 11-12). En los dos párrafos siguientes, con los cuales concluye Capmany el apartado dedicado a la sinonimia, procede al examen de unas cuantas palabras castellanas consideradas generalmente como sinónimas.

Los textos que acabamos de cotejar nos proporcionan, por una parte, lo esencial de la teoría de Girard, varias veces evocada en el presente trabajo, y por otra parte, su versión castellana, casi siempre digna de elogios. Dicha versión constituye por cierto una perfecta ilustración del consejo que, siendo censor, Capmany daba - en el mismo año en que publicaba la Filosofía de la elocuencia - a los plagiarios de obras francesas, que tendian a multiplicarse: «[...] Deberían por lo menos, para encubrir su plagio, esmerarse en traducir con tal soltura y propriedad de estilo, que su traducción pareciese original» ${ }^{21}$. A esas recomendadas virtudes, añade en el caso preciso de esta versión una prueba de gran habilidad, al evitar una traducción totalmente literal, merced a unas cuantas omisiones y adiciones.

Una de las omisiones - la primera - provoca la curiosa desaparición de una breve frase en la cual afirmaba Girard que la «feliz elección» de las voces también podía aplicarse al discurso científico: a Capmany le habrá parecido sin duda más prudente suprimir esa referencia a l'étude des sciences, que no formaba parte de la ortodoxia española de su tiempo. Se nota, por otra parte, que están omitidas las comparaciones y metáforas, excepto el símil del banquete, algo simplificado. Pero no se puede saber con certeza si esas imágenes las descartó Capmany para abreviar el texto, ciñéndose a la reflexión teórica, o para introducir en su lugar ejemplos castellanos, como ocurre en una ocasión. Es de reconocer que algunas metáforas resultan muy difíciles de traducir, aun para un buen conocedor del idioma francés. $E$ incluso cabe pensar en un posible deseo de disimular el plagio, eliminando figuras

21 Censura de Noticia y población de las colonias inglesas en la América septentrional, de Franciso Alvarez, comentada en mi artículo «Antonio de Capmany censeur à la Real Academia de la Historia (1776-1802)", Mélanges de la Casa de Velázquez, XIX, 1983, p. 250. 
originales que no podían pasar inadvertidas y, por tanto, habían de recordar de manera harto explícita el tratado de Girard.

Algunos pasajes, como la conclusión del segundo párrafo, están omitidos porque tal vez se expresan en ellos ideas evocadas anteriormente con bastante precisión: no aportan ningún elemento nuevo a la demostración. Más extraña parece, en cambio, la omisión del párrafo siguiente, en el cual especifica Girard el campo de aplicación de su teoría: no está traducido, quizás porque está construido a partir de una metáfora floral algo compleja. En cuanto a la última omisión, es en realidad una sustitución, puesto que, para terminar, Capmany abandona a Girard por La Bruyère. Aparentemente, no quiere concluir el apartado sobre los sinónimos sin traducir por lo menos una frase de aquel pasaje que Du Marsais había sido el primero en citar ${ }^{22}$. Dicho pasaje, reproducido por varios sinonimistas, se había convertido en una referencia casi obligada.

Entre las adiciones, menos numerosas que las omisiones, puede notarse una advertencia - poco original, desde luego- sobre la relación que existe entre el uso excesivo de sinónimos y la incapacidad para distinguirlos. Pero la aportación de Capmany consiste esencialmente en los ejemplos que, insertados de manera muy oportuna, le dan al texto un aire castizo y, además, vienen a ser una necesidad en una obra de declarada intención didáctica, como lo es la Filosofía de la elocuencia. Dichas adiciones no pueden, sin embargo, considerarse como elementos de una reflexión personal ni evitar, por consiguiente, que se tenga ese apartado dedicado a los sinónimos por un indiscutible plagio. Tan indiscutible, por cierto, que resulta muy extraño que nunca haya sido (que yo sepa) denunciado como tal ${ }^{23}$.

A modo de explicación -y no de justificación-, puede aducirse que Capmany había puesto muchas esperanzas en esta obra, como lo revelan el ambicioso título que le dio y ciertas gestiones que hizo para

22 Du Marsais, op. cit., p. 245 de la ed. de 1977, ya citada. He aquí el pasaje de La Bruyère en su integridad: «Entre toutes les différentes expressions qui peuvent rendre une seule de nos pensées, il n'y en a qu'une qui soit la bonne. On ne la rencontre pas toujours en parlant ou en écrivant; il est vrai néanmoins qu'elle existe, que tout ce qui ne l'est point est faible et ne satisfait point un homme d'esprit qui veut se faire entendre» (I, 17).

23 No es éste el único caso de plagio que se advierte en la Filosofía: de manera general, debe mucho Capmany a Du Marsais, como he de puntualizarlo en una próxima ocasión. 
que el libro llegara a manos del mismo d'Alembert ${ }^{24}$. Quería que su $\mathrm{Fi}$ losofía participara precisamente del nuevo espíritu «filosófico», y así no ha de sorprender que, para el examen de la sinonimia, acudiera a un tratado unánimamente aplaudido y ya imitado por alemanes, italianos e ingleses ${ }^{25}$.

Unos diez años más tarde, Capmany volvió a exponer los aspectos esenciales de la teoría de Girard en las «Observaciones» incluidas en el primer tomo de su Teatro histórico-crítico de la eloqüencia española ${ }^{26}$. Tal insistencia bien podría corresponder al hecho de que muchos literatos españoles todavía se resistían a considerar los sinónimos como problema, resistencia motivada tal vez por el cariz afrancesado de la nueva doctrina. En estas páginas, se encuentra además la expresión de un deseo: que se elabore, en España, un verdadero diccionario de sinónimos, ideado como un «diccionario filosófico de todas las finezas y modificaciones del lenguaje, sin cuyo auxilio es imposible dar principios fijos a la propriedad y corrección de idioma alguno» ${ }^{27}$. Un diccionario «filosófico», es decir, un diccionario que aplicaría al estudio de los sinónimos castellanó las conclusiones de la reflexión crítica sobre la sinonimia, en vez de acumular indistintamente, en torno a una noción, voces y frases más o menos afines, como aparentemente lo proyectaba Iriarte. Lo arduo de la empresa no hizo retroceder al mismo Capmany, puesto que figuraba, entre los manuscritos que estaban inéditos cuando salió de Madrid en 1808, el Plan alfabético de un diccionario de sinónimos castellanos, en el cual estaban reunidas nada menos que 1.645 voces $^{28}$. De este arsenal entresacaría los muchos ejemplos que, en la edición londinense de la Filosofía, aumentan considerablemente el vo-

24 Capmany había pedido a Viera y Clavijo, entonces residente en París, que entregara a d'Alembert un ejemplar de la Filosofía, con una carta suya. D'Alembert no se dignó contestar a Capmany y ni siquiera recibir a Viera: véase en mi artículo «España en las Nouvelles de la République des Lettres et des Arts (1777-1788)», Boletín de la Biblioteca Menéndez Pelayo, año XLIX, 1973, p. 323. Véase supra, nota 17.

Publicado en Madrid, por Antonio de Sancha, 1786-1794. Capmany trata de los sinónimos en el último de tos apartados de las «Observaciones críticas sobre la excelencia de la lengua castellana», pp. CCXVI-CCXXII del tomo I. Op. cit., p. CLXX del tomo I.

La lista de estos manuscritos está reproducida por Guillermo Forteza en su Juicio crítico de las obras de don Antonio de Capmany y Montpalau, Barcelona, Tomás Gorchs, 1857, pp. 65-68. El Plan alfabético de un diccionario de sinónimos castellanos está registrado por La Viñaza, op. cit., tomo III, p. 864, núm. 1.088. 
lumen de los párrafos dedicados a los sinónimos ${ }^{29}$. $\mathrm{Y}$ ello es la mejor prueba del gran interés que tuvo, durante más de treinta ños, por ese problema tan propio de su siglo.

Este siglo se acaba sin que se publique en España -ni, por cierto, en Francia ${ }^{30}$ - aquel verdadero diccionario de sinónimos que deseaba Capmany. Pero, en 1789, en un ensayo redactado por José López de la Huerta, puede percibirse un eco de las ideas expuestas en la Filosofía. El mismo título de este ensayo: Examen de la posibilidad de fijar la significación de los sinónimos, refleja la modestia del autor, así como una clara conciencia de las dificultades de semejante estudio. El Examen consta de 160 artículos, en los cuales están analizadas, según los casos, dos o tres palabras sinónimas. Puede parecer poco, si comparamos con el número de voces registradas en los tratados que se publicaban entonces en Francia ${ }^{31}$; pero López de la Huerta no era gramático, sino secretario de Embajada, simplemente deseoso de plantear - y solucionarde modo práctico este problema.

La breve introducción que precede al estudio propiamente dicho empieza con estas palabras:

Este análisis de algunos de los muchos sinónimos de la lengua castellana es
puramente fruto de una mera diversión, a que me inclinó la curiosidad de ver
si se podía imitar en nuestra lengua lo que algunos escritores franceses han
pretendido hacer en la suya, esto es, fijar la exacta y peculiar significación de
cada una de aquellas voces que el uso, y aun la autoridad, han aplicado hasta
ahora a las mismas ideas, pero que, examinadas con todo rigor, explican la
idea común, o con diferentes relaciones, o descubriendo en ella otras ideas

29 Filosofía de la eloqüencia, Londres, Impr. de H. Bryer, 1812, pp. 109-122. Esta nueva edición estaba ya preparada en 1808 , como consta en la mencionada lista de manuscritos entonces inéditos, donde está calificada de obra «aumentada, corregida, ilustrada y, en una palabra, refundida enteramente» (en Guillermo Forteza, op. cit., p. 65).

30 No consideraba Beauzée como diccionarios sus reediciones muy aumentadas del tratado de Girard, puesto que, en 1799 todavia, expresaba el siguiente deseo: «On souhaiterait [...] que les gens de lettres qui sont en état d'entrer dans les vues fines et délicates de cet ingénieux écrivain, voulussent bien concourir à la perfection de l'édifice dont il a en quelque manière tracé le plan et posé les premiers fondements. Il en résulterait quelque jour un excellent dictionnaire; ouvrage qui, envisagé sous ce point de vue essentiel, nous manque jusqu'à présent" (Synonymes françois [...]. Nouvelle édition [...], Lyon, Impr. Leroy, An VII [1799], tomo II, pp. 14-15). Condillac había elaborado un diccionario de sinónimos para su discípulo, el príncipe de Parma; pero no llegó a publicarse hasta 1951 (por Mario Roques). Para el estudio de la sinonimia en Francia, en el siglo XVIII, véase Sylvain Auroux, La sémiotique des Encyclopédistes, París, Payot, 1979, pp. 268-273.

31 La primera edición del tratado de Girard (1736) constaba de unos 350 artículos; y, en la última reedición del siglo XVIII (citada en la nota anterior), llegan a 715 los que propone Beauzée. 
accesorias que la modifican, de modo que, si no varían siempre el riguroso sentido, a lo menos dan diferente energía y exactitud a la frase, y por consiguiente no se pueden usar indistintamente una por otra con igual propiedad en todos los casos.

Y en las páginas siguientes, expone muy claramente los principios en los cuales funda su método analítico.

López de la Huerta no ignoraba, naturalmente, el interés que Capmany había manifestado ya por el problema de los sinónimos: cita un pasaje de la Filosofía de la elocuencia, pero sin especificar, ni el título de la obra, ni el nombre del autor, a quien alude a través de una fórmula tan vaga como halagüeña: «[...] dice uno de nuestros mejores escritores modernos» ${ }^{32}$. Fórmula muy hábil, que le permite evocar al escritor catalán sin revelar el plagio, que no le habría escapado, dado su perfecto conocimiento de la teoría de Girard.

A pesar de la sinceridad de su declaración preliminar, ésta le vale pronto --ipara colmo de ironía! - el reproche de haberse contentado con plagiar a los más famosos sinonimistas franceses ${ }^{33}$. Reproche totalmente injustificado, puesto que no pretendía López de la Huerta renovar la teoría de los sinónimos, sino ponerla en práctica, aplicándola a la lengua española. Desde este punto de vista, su obra es perfectamente original y, para cerciorarse de ello, basta con imitar a un sinonimista posterior, ya aludido, quien compara algunos artículos sacados de los tratados franceses con los que les corresponden en el Examen de López de la Huerta ${ }^{34}$. Este cotejo, amplificado a otros muchos casos, demuestra que en el método puede efectivamente notarse la influencia de dichos tratados (en particular en la referencia implícita al uso). Pero este cotejo demuestra también que los comentarios de López de la Huerta no deben nada a sus antecesores; $y$, en no pocos casos, son distintas las palabras examinadas.

32 Examen de la posibilidad de fijar la significación de los sinonimos de la lengua castellana, Madrid, Impr. Real, 1799, p. VIII. El pasaje citado corresponde a unas observaciones sobre «el valor numeral de las voces», sin olvidarse el símil del banquete (Filosofía de la eloqüencia, p. 50 de la ed. de 1777; texto reproducido en la p. 10 del presente trabajo). Sobre el tratado de López de la Huerta, consúltese el artículo de Juan Antonio Tamayo «Fortuna de un libro sobre sinónimos españoles [...]», Bibliografía Hispánica, año IV, abril 1945, núm. 4, pp. 242-253.

33 Tenemos noticias de este reproche únicamente por la siguiente alusión de Santiago Jonama: «He oído deprimir varias veces el mérito de aquel autor, diciendo que para la composición de su obra no había tenido más que acomodar o traducir al lenguaje castellano las diferencias que en el francés habían establecido Girard, Beauzée, Roubaud, etc.) (op. cit., p. XIII).

Ibíd., pp. XVI-XX. 
El mejor argumento al respecto lo da, por cierto, el mismo autor en una serena respuesta que les hace a sus detractores, en la segunda edición de su libro. Afirma entonces que no puede concebirse el plagio en el análisis de los sinónimos de distintos idiomas, porque «es casi imposible adaptar a una lengua el mismo espíritu, carácter y modificaciones de las voces de las otras» ${ }^{35}$. Y, a pesar de esos ataques infundados, los lectores españoles no dejaron de apreciar los méritos de esta obra, que se reeditó varias veces (en $1799,1807,1811$, etc.) y que sigue siendo hoy de aprovechable consulta.

\section{El indefinible uso}

Al pasar de la teoría a la práctica, todos los discípulos de Girard, cualquiera que fuera su nacionalidad, habían de tropezar con dos dificultades esenciales, que revelan algunas insuficiencias en una doctrina tan generalmente aceptada.

La primera procede de la ausencia de un verdadero criterio para seleccionar los propios sinónimos. Estos podrían, por consiguiente, multiplicarse indefinidamente, puesto que la proximidad semántica no tiene límites a priori. Fue aparentemente Diderot el único en advertir la existencia de este problema, que él plantea con perfecta nitidez:

Nous ne finirons pas nos observations sur la langue, sans avoir parlé des synonymes. On le multiplieroit à l'infini, si on ne commençoit par chercher quelque loi qui en fixât le nombre.

$Y$, a continuación, propone precisamente esta «ley»:

Il ne faudra traiter comme synonymes que les termes que la Poésie prend pour tels; afin de remédier à la confusion qui s'introduiroit dans la langue par l'indulgence que l'on a pour la rigueur des lois de la versification. Il ne faudra traiter comme synonymes que les termes que l'art oratoire substitue indistinctement les uns aux autres; afin de remédier à la confusion qui s'introduiroit dans la langue, par le charme de l'harmonie oratoire qui tantôt préfère et tantôt sacrifie le mot propre $[\ldots]^{36}$.

Todos los sinonimistas del siglo XVIII admiten que las necesidades del arte poética u oratoria pueden dificultar, a veces, una imprescindible distinción entre palabras de sentido parecido. Pero, en este mal ineludible, halla el filósofo varias ventajas: la más evidente es que las obras de

35 Examen $[\ldots], 4 .^{a}$ ed. corregida y aumentada, Valencia, Impr. de José Estevan, 1811 , tomo I, p. V.

36 Encyclopédie, art. «Encyclopédie», tome V [1755], p. 640 b. 
aquellos poetas y oradores constituyen una fuente abundante y segura de voces y expresiones sinónimas; otra, menos inmediata, consiste en la posibilidad de corregir, por un análisis detenido de dichas voces y expresiones, la confusión que podía provocar su uso indefinido en textos de reputados autores.

A esta primera dificultad, mencionada (si no descubierta) por Diderot únicamente, se añade una segunda que suscita comentarios más numerosos. Nace de una interrogación primordial, que ni siquiera está formulada por Girard: ¿cómo debe procederse en el examen de las palabras tenidas por sinónimas? $\mathrm{O}$, más precisamente: ¿en qué fundar la necesaria distinción entre idea principal e ideas accesorias? Esta nueva ausencia de criterio fijo podía justificar que se juzgaran arbitrarias las definiciones propuestas para diferenciar los sinónimos. Este grave reparo provoca, por parte de Beauzée, las aclaraciones siguientes:

Je remarquerai [...] que ce qu'enseigne l'abbé Girard au sujet des différences qui distinguent les synonymes n'est rien moins qu'arbitraire; qu'il est fondé sur le bon usage de notre langue et qu'il ne s'agit, pour en établir les décisions sur cet objet, que d'en extraire avec intelligence les preuves répandues dans nos ouvrages les plus accrédités et les plus dignes de l'être ${ }^{37}$.

En esta advertencia queda definido por primera vez, con la noción de «uso» (reducido por Beauzée al «buen uso»), el criterio implícitamente aplicado por Girard (al menos según su discípulo). En otro lugar, el gramático especifica el contenido de esta noción, declarando:

Je dirai que le bon usage est la façon de parler de la plus nombreuse partie de la cour, conformément à la façon d'écrire de la plus nombreuse partie des auteurs les plus estimés du temps ${ }^{38}$.

Definido de este modo, el uso deja de ser una característica lingüística; se transforma en una norma sociocultural para cuantos quieren conocer con exactitud la lengua de su época y emplearla con elegante precisión.

Tal teoría corresponde a la necesidad, claramente sentida por Beauzée, de puntualizar la noción de uso, que hasta entonces sólo había servido de punto de referencia implícita o confusamente. De esta vaguedad ofrece Dendo y Avila un buen ejemplo, al valerse de la expresión «uso común» sin aclararla nunca. Si no sabemos exactamente quién le sirve de guía en su reflexión sobre los sinónimos, no cabe ninguna duda (además lo declara él mismo expresamente) de que no son ni

Ibid., art. «Synonyme», tome XV [1765], p. 758 a.

38

Ibid., art. «Usage», tome XVII [1765], p. 517 a. 
pueden ser los mejores autores de los siglos pasados. Este criterio parece ser también el de López de la Huerta, quien confiesa que las definiciones propuestas en su Examen están muchas veces en desacuerdo con la «autoridad»: alusión probable - y prudente- al diccionario de la Academia, siendo presentada luego dicha «autoridad» como la de «nuestros clásicos», cuyas obras constituyen precisamente el corpus de ejemplos del llamado Diccionario de Autoridades. López de la Huerta evoca indirectamente el inconveniente que representa el hecho de referirse tan sólo a unos autores considerados como clásicos para determinar el sentido de palabras afines. Efectivamente, entre dichos autores, no imperaba la exigencia que los progresos del siglo ilustrado han hecho necesaria, a nivel de la reflexión y de la comunicación:

No se puede dudar que cada día se va fijando más la significación de las voces, y distinguiéndose por su medio, con mayor exactitud, las más delicadas percepciones del entendimiento. Este es un efecto que naturalmente y sin esfuerzo producen los progresos de la literatura, de las artes, de la sociabilidad, y el comercio o recíproca comunicación de las ideas; porque la mayor extensión y claridad que éstas adquieren obligan a multiplicar, distinguir y fijar los signos que las hacen perceptibles ${ }^{39}$.

Referirse únicamente a «la autoridad de nuestros clásicos» resulta, por tanto, no sólo improcedente, sino erróneo: dichos autores ya no representan el «uso».

Se encuentra también una censura de la «autoridad» en la segunda edición de la Filosofía de la elocuencia ${ }^{40}$. Pero Capmany hace esta censura de modo mucho más directo, con la seguridad de un filólogo reconocido. Primero designa muy claramente al acusado: el diccionario de la Academia. Y demuestra luego, con numerosos ejemplos, que los autores de dicho diccionario se contentan casi siempre con reunir voces de sentido parecido en torno a una idea común (lo que hoy llamamos la definición sinonímica), en vez de apuntar la significación precisa de cada término. No denuncia Capmany un error en la elección de los textos de referencia, sino una lamentable indiferencia ante el problema de la sinonimia ${ }^{41}$. Conviene advertir, para disculpar un tanto a los académicos, que por los años en que redactaron su diccionario, acabado ya en 1739, no se había difundido la teoría de Girard. Pero, en la reedición

39 Examen [...], 1. a ed. cit., p. XI.

40 Op. cit., pp. 113-115.

41 Reveladoras son al respecto las definiciones que encontramos en el Diccionario de Autoridades (tomo VI, 1739), s. v. synonimia («la repetición de voces de un mismo equivalente y significado») y synónimo, ma («adj. que se aplica a los nombres, que con poca diferencia explican lo mismo»). 
de 1780 (en un volumen, sin las «autoridades»), no tuvieron en cuenta esa teoría, la cual, por cierto, está combatida en España hasta finales del siglo XVIII, e incluso más tarde ${ }^{42}$.

A la autoridad del diccionario académico, Capmany opone la autoridad del «uso». Es de observar que este concepto de «uso» está totalmente ausente de los párrafos dedicados a los sinónimos en la primera edición de la Filosofía, y que está, en cambio, omnipresente en los párrafos correspondientes de la edición londinense, muy distinta en varios aspectos y en particular por la abundancia de ejemplos castizos. En esta segunda edición, el examen de la sinonimia deja de ser un mero plagio de Girard, adaptándose — precisamente- al «uso» español. A este «uso» acude sistemáticamente Capmany para los numerosísimos casos de voces sinónimas que estudia, convencido de que, si obedecemos a «la regla sabia del uso», «este maestro nos dará la particular y propia definición de cada una» ${ }^{43}$. Y advierte, de manera algo perentoria:

Saber su lengua, no es sólo saber su sintaxis y la nomenclatura de millares de voces, si se ignora la aplicación que se ha de hacer de ellas, muchas veces más por el uso que por razón ${ }^{44}$.

Viene a continuación una larga serie de ejemplos, que prueban perfectamente cuán difícil resulta a veces explicar de modo razonado lo que d'Alembert define como «des bizarreries de la langue, sur lesquelles est fondée en partie la connaissance des synonymes» ${ }^{45}$. Por lo tanto, el uso puede ser, según los casos, o «regla sabia», o «bizarrerie de la langue».

Tal ambigüedad explica, tal vez, que Capmany no se atreva a definir con precisión el «uso», el cual, en estas páginas, se confunde en realidad con los ejemplos; es decír, con los datos que proporcionan una gran experiencia y una larga observación de la lengua. Pero solamente

42 Véase el comentario del P. Esteban de Terreros y Pando, en su Diccionario castellano con las voces de ciencias y artes [...]. Madrid, 1786-1793, s. v. sinónimo: «Los que condenan las voces sinónimas condenan a toda la antigüedad; y usadas con discreción ayudan a que el período sea más numeroso, más eficaz y claro» (tomo III [1788], p. 501 a). Y, en 1811, López de la Huerta advierte: «La distinción de los sinónimos es un fruto nuevo, que hace poco que cultivamos, cuyo gusto no se debe, ni se puede introducir por fuerza, ni pretender que agrade a todos, porque a pocos les gusta el que vengan a disputar la cómoda negligencia con que se han explicado toda la vida, sin andar buscando perfecciones para que los entiendan» (4. ${ }^{\text {a }}$ ed., ya citada, de su Examen, tomo I, pp. XIV-XV).

Filosofía de la eloqüencia, ed. de 1812, op. cit., p. 114.

Ibíd., pp. 116-117.

45 Encyclopédie, art. «Dictionnaire», tomo IV [1754], p. 960 b. 
de la lengua de su siglo, puesto que en el examen de los sinónimos nunca alude Capmany a los autores de los siglos anteriores, ni siquiera a los que presenta como modelos de elocuencia en su Teatro. Lo cierto es que el uso, para Capmany, no puede reducirse al «buen uso», entendido como el de los autores clásicos o como el de la Corte, según afirmaba Beauzée. Prefiere una concepción mucho más general, que hace del uso un criterio cómodo y (aparentemente) seguro para el estudio de la sinonimia.

Concepción muy general, desde luego, pero más cauta que la que rige un Ensayo sobre la distinción de los sinónimos de la lengua castellana que, en 1806, publica Santiago Jonama, ministro de la Real Hacienda en las Islas Filipinas. Jonama pretende valerse de la moderna lógica para demostrar en qué consiste exactamente el uso, que él califica - como Dendo y Avila - de «común». Pero su demostración carece de rigor y no resulta en aboluto convincente. El «uso común», llamado también «uso del día», está equiparado con el «buen lenguaje»y, naturalmente, no debe confundirse con «el uso común de la Puerta del Sol y de los cafés». Finalmente, la definición «lógica» es la siguiente:

El uso común [...] es la pluralidad de los que hablan con conocimiento de materia [el subrayado no es mío]: de modo que en voces y frases de física será la pluralidad de los buenos físicos; en lo perteneciente a pintura, la pluralidad de los buenos pintores, y así en todas las demás materias ${ }^{46}$.

Medio siglo después del Ensayo de Dendo y Avila, un sinonimista explicitaba por fin su concepto del uso; pero la definición del ministro filólogo, sorprendente e incluso paradójica (el uso común, ¿lengua de peritos?), era por lo menos discutible ${ }^{47}$.

Beauzée había señalado dos caminos a los literatos deseosos de aplicar y ampliar la teoría de Girard:

Les uns peuvent continuer sur le plan de l'abbé Girard, en assignant les caractères distinctifs des synonymes avec précision, et en y adaptant des exemples qui en fassent sentir la justesse et qui montrent l'usage qu'il en faut faire. pp. 23-40 de la Introducción.

47 Discutible y, por cierto, discutida: se publicó en el Diario de Madrid del 21 de mayo de 1806, una larguísima Carta sobre los sinónimos de la lengua castellana que escribió Don Santiago Jonama, redactada con mucha sorna por Juan Gualberto González (texto reproducido en las Obras en verso y prosa de este autor, Madrid, 1844, tomo III, pp. 161-192; para el tema del «uso», véanse en particular las pp. $167-168$ y 188-189.) 
Les autres recueilleront les preuves de fait, que leurs lectures pourront leur présenter dans nos meilleurs écrivains, de la différence qu'il y a entre plusieurs synonymes de notre langue ${ }^{48}$.

En la España de las Luces, no fueron muchos los sinonimistas. Entre éstos, los más constantes - López de la Huerta y Capmany - siguieron el primero de los caminos indicados. Y por este camino, fueron recogiendo con buena mano ese material lingüístico sin el cual la filosofía de la sinonimia queda totalmente huera.

48 Synonymes françois..., nueva ed. ya çitada (1769), tomo II, Prefacio, p. 15. 


\section{APENDICE}

\section{TEXTO DEL PROYECTO DE UN DICCIONARIO \\ DE SINONIMOS Y EQUIVALENTES \\ REDACTADO POR TOMAS DE IRIARTE}

Este proyecto es un texto semi inédito, puesto que algunas frases -entre las más interesantes, desde luego- fueron ya extractadas y reproducidas por Fernándo Lázaro Carreter ${ }^{49}$, a partir de un manuscrito conservado en la Biblioteca Nacional de Madrid (ms. 12.965, núm. 30). Este manuscrito es muy probablemente autógrafo (y se da por tal en dicha biblioteca), porque todo es de una misma pluma: el texto, las muchísimas enmiendas al mismo, y los borradores que están adjuntos. Pero no he podido cotejarlo personalmente con indudables autógrafos de Tomás de Iriarte.

Este manuscrito puede fecharse, como se ha visto, entre 1770 y 1775 .

La Viñaza, en su catálogo monumental ${ }^{50}$, registra un Diccionario de sinónimos, copiado del que el Sr. D. Juan de Iriarte formó y dexó en su Librería, fechándolo (sin ninguna justificación) en 1774. Pero no cita el proyecto de Tomás de Iriarte, y el Diccionario de sinónimos atribuido a Juan de Iriarte era ya, a finales del siglo XIX, un manuscrito perdido, cuya existencia sólo consta en noticias indirectas. ¿Conocería el fabulista dicho manuscrito, obra probable de su tío? ¿Habrá querido aprovechar este trabajo para su propio Diccionario de sinónimos $y$ equivalentes? Es inútil seguir con estas preguntas, puesto que por ahora no podemos contestarlas ${ }^{51}$.

Lo cierto es que el proyecto que redactó Tomás de Iriarte era un proyecto muy ambicioso, como lo prueban las declaraciones que podrán leerse a continuación. Y era también un proyecto a punto de concretarse, porque viene, inmediatamente después de estas declaraciones, una «Explicación de las señales y abreviaturas usadas en este diccionario» (fol. 9 r.).

Op. cit., p. 81. Estas frases aparecen entre corchetes en la presente edición. Op. cit., tomo III, p. 864, núm. 1.086.

51 Ningún elemento de respuesta encontramos desgraciadamente en el libro, punto menos que exhaustivo, de Emilio Cotarelo y Mori, Iriarte y su época, Madrid, Rivadeneyra, 1897. 
No se reproduce aquí esta «Explicación». Tampoco se reproduce, por razones ya expresadas, la lista de «Frases y refranes» que ocupa las cinco últimas hojas del manuscrito. Sólo se dan a conocer las hojas que revelan -explícita o implícitamente- una teoría del sinónimo.

En la transcripción de dichas hojas, se moderniza la grafía y se resuelven las abreviaturas, conservándose rigurosamente las características morfológicas y sintácticas del original.

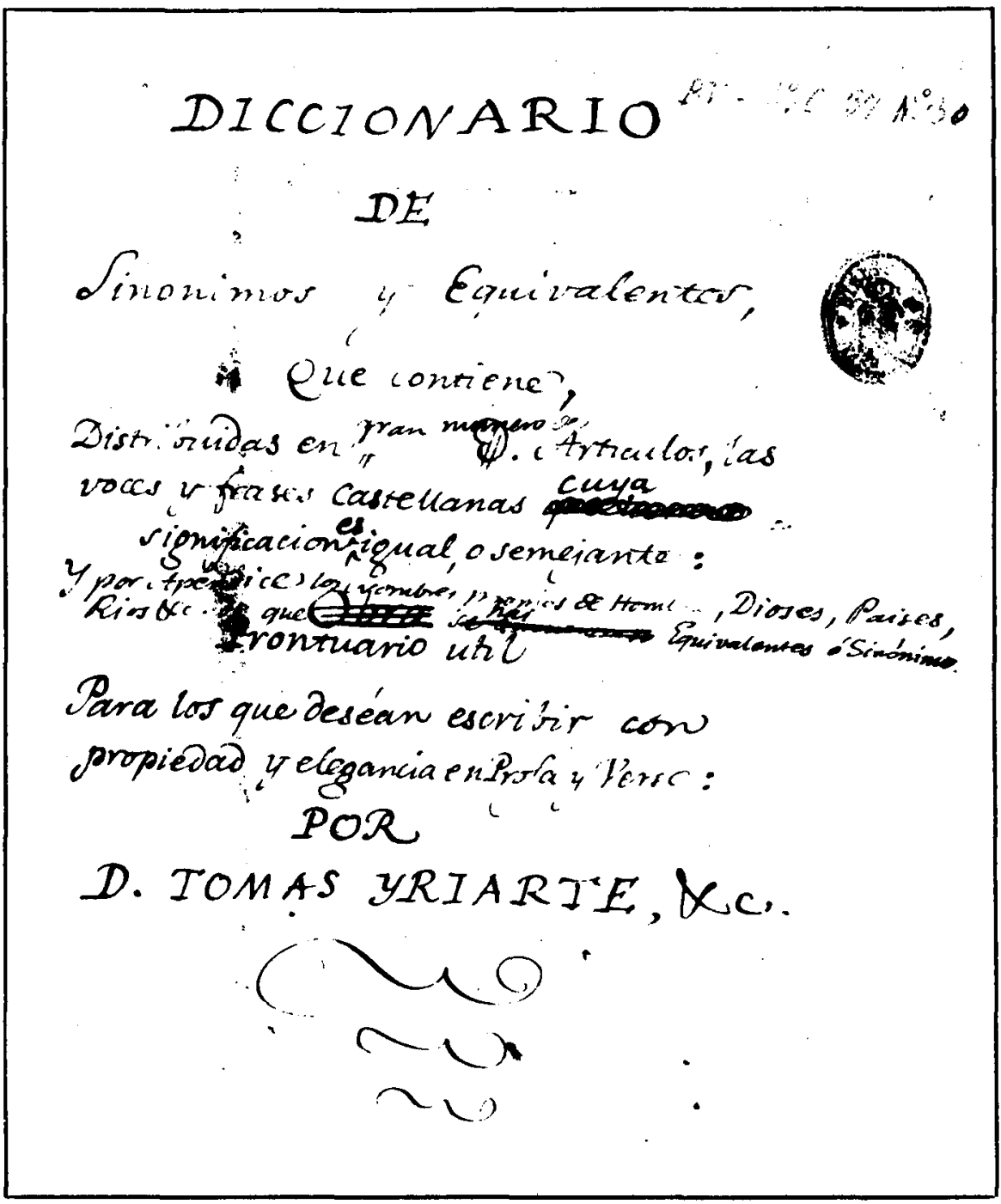

Portada del manuscrito editado (Biblioteca Nacional, ms. 12.965, núm. 30) 
fol. 1 r. DICCIONARIO / DE / SINONIMOS Y EQUIVALENTES, / QUE CONTIENE, / DISTRIBUIDAS EN GRAN NUMERO DE ARTICULOS, LAS / VOCES Y FRASES CASTELLANAS CUYA / SIGNIFICACION ES IGUAL, O SEMEJANTE. / Y POR APENDICE LOS NOMBRES PROPIOS DE HOMBRES, DIOSES, PAISES, / RIOS, ETC. DE QUE HAY EQUIVALENTES O SINONIMOS. / PRONTUARIO UTIL / PARA LOS QUE DESEAN ESCRIBIR CON / PROPIEDAD Y ELEGANCIA EN PROSA Y VERSO. / POR D. TOMAS DE IRIARTE, ETC. 52

fol. 2 r. IDEA DE ESTE DICCIONARIO Y ADVERTENCIÀS PRECISAS PARA EL USO DE EL.

No se ha impuesto la sabia política obligación más justa, después de la de mantener las posesiones de un estado y procurar su interior felicidad y riqueza, que la de atender a la conservación y lustre del lenguaje ${ }^{53}$ nacional, ya sea porque con lo abundante y expresivo de él se facilitan las ciencias y artes, sin las cuales jamás prosperan los imperios, ya porque una gran parte del crédito y gloria que éstos gozan suele depender de la mayor o menor fama que su idioma y los libros escritos en él logran en las naciones estranjeras. Así pues, este cuidado en cultivarle y enriquecerle, sólo podrá parecer ocioso a los que no hayan reflexionado que la decadencia de las lenguas siempre ha sido seguro indicio de la decadencia de las repúblicas.

Esta consideración, unida a mi deseo de hacer algún bien a la Patria, es la que principalmente me ha incitado a emprender la prolija obra de este Dic-

fol. 2 v. cionario, [que al paso que recopila y gradúa las voces y locuciones / castellanas o sinónimas o equivalentes, demuestra la fecundidad de nuestra lengua y favorece a los ingenios que aspiran a usar de ella con variedad, energía y buena elección.

Y pues debo advertirles aquí cuáles son, a mi parecer, las utilidades que les ofrece este vocabulario, las reduciré todas a las siguientes:

I. $^{a}$ Los escritores que necesiten variar una misma idea con diversas palabras, por no incurrir en repeticiones fastidiosas, hallarán junto a la dicción que busquen todas las que significan lo mismo que ella: quiero decir los que propiamente se llaman sinónimos, de los cuales hay en castellano una copiosa porción, sin embargo de la opinión que pretende no haberlos verdaderos y legítimos en ningún idioma $\left.{ }^{54}\right]$. Tales son, por ejemplo, asno, burro, borrico y jumento; partera y comadre; guitarra y vihuela; cerdo, puerco, cochino y marrano; motín, tumulto, sedición y levantamiento, etc., entre cuyas voces

52 Este título es el resultado de varias correcciones que constan en las tachaduras y en los añadidos de la primera hoja del manuscrito (véase lámina). Se advierte principalmente que la finalidad práctica de este Diccionario de sinonimos y equivalentes queda subrayada con la sustitución de Obra por Prontuario útil; además, serían inicialmente unos millares los artículos previstos puesto que primero había escrito Iriarte: «en [espacio en blanco] [abreviatura de mil]», prefiriendo luego una formulación menos precisa: «en gran número de». Programa desde luego excesivamente ambicioso, como suele ser el de casi todos los autores de diccionarios; pero no ha de olvidarse que se debe a un hombre de unos veinte affos, que incluso quiere competir con los académicos (véase infra, fol. 8 r.).

53 En el original: «de lenguaje».

54 Lázaro Carreter pone: «en castellano», en vez de «en ningún idioma». Unas pocas líneas supra, transcribe: «lo que propiamente se llaman sinónimos» y, en lo alto del fol. $2 \mathrm{v}$, «sinónimas o equivalentes», olvidando una primera conjunción $o$ (que sirve, sin embargo, para expresar una distinción entre ambos conceptos). 
y otras semejantes no puede hallar diferencias el discernimiento más sutil, pues expresan la propia idea o cosa en todas ocasiones y respectos.

fol. $3 \mathrm{r}$. II. ${ }^{\mathrm{a}}$ [Los que buscan alguna palabra para denotar con una absoluta propiedad lo que conciben, hallarán un conjunto de vocablos equivalentes en que escoger, con la seguridad de que si hay en la lengua la voz que se requiere, la han de encontrar en el número de las otras que tienen alguna semejanza o analogía] con ella. Supongamos, por ejemplo, que buscando un adjetivo con que calificar la bondad de una cosa, nos ofrece el artículo bueno más de cuarenta adjetivos, no sinónimos, pero sí equivalentes, los cuales unos con mayor y otros con menor fuerza determinan varios grados de bondad. Si la excelencia de lo que se va a celebrar, sólo merece un mediano elogio, se la aplicará uno de los epítetos bueno, bello, lindo, gracioso, pulido, hermoso, etc. Si se ha de exagerar más, diremos perfecto, superior, excelente, exquisito, primoroso, eminente, consumado, sobresaliente, arrogante, etc. Si la cosa que se ha de aplaudir se considera como única y rara, escogeremos en aquel artículo las voces singular, particular, especial, sin-par, cual ninguno,

fol. $3 \mathrm{v}$. sin segundo, selecto, etc. Si se la contempla grande y sublime, / usaremos, según convenga, de los adjetivos magnifico, insigne, noble, alto, grandioso, eximio, egregio, soberbio, etc. Si se quiere atender al valor de ella, la llamaremos preciosa, apreciable, estimable, etc., y si a la admiración que merece, maravillosa, portentosa, prodigiosa, pasmosa, asombrosa o admirable.

III. $^{a}$ [Los poetas que, o bien necesitan consonantes, o bien palabras que por el número de.sus sílabas y por la calidad de sus acentos se acomoden bien al verso, hallarán copia de voces de distintas terminaciones, sílabas y cantidades.] Sirva de ejemplo el mismo artículo bueno ya citado. Allí se presentan los consonantes excelente, eminente, sobresaliente, valiente; hermoso, primoroso, precioso, gracioso, maravilloso, prodigioso, portentoso, pasmoso, asombroso; singular, particular, sin-par; consumado, aventajado; selecto, perfecto; admirable, apreciable, y otros muchos. Hallarán adjetivos de dos sílabas como bello, bravo, noble, grande, lindo, etc.; de tres, como her-

fol. 4 r. moso, eximio, egregio, / insigne, soberbio, etc.; de cuatro, como eminente, exquisito, excelente, admirable, etc.; de cinco, como maravilloso, sobresaliente, aventajado. Unos se ofrecerán con el final agudo, como singular, superior, sin-par; otros esdrújulos, como magnífico, y los superlativos que pueden formarse de los mismos nombres ya mencionados, como bellísimo, preciosísimo, primorosísimo, admirabilísimo.

IV. $^{\text {a }}$ [Los buenos escritores de prosa que han de estudiar la armonía de los períodos casi con tanto esmero como estudian los poetas la de sus versos, lograrán no menor ventaja en aquella variedad de voces de diversa cadencia y número de sílabas ${ }^{55}$.]

$V{ }^{a} \quad$ Unos y otros hallarán distinguidas con diferentes señales las voces y frases del estilo poético y sublime; las del más familiar o bajo; las del medio y

fol. $4 \mathrm{v}$. corriente; muchas de las anticuadas y de / las raras que pueden usarse en ciertos casos, y algunas de las introducidas modernamente. Al fin de este prólogo se expresará cuáles son aquellas señales y lo que debe significar cada una de ellas.

Explicadas así las varias circunstancias útiles que se ha procurado reunir en este Nuevo Diccionario, resta apuntar algunas particularidades que podrán observar en él los curiosos.

Exprésanse generalmente sólo las terminaciones masculinas; pues cualquiera que tenga mediana inteligencia de nuestro idioma formará fácilmente de enfermo enferma, de parlero parlera, de lector lectora, etc.

55 En este párrafo, Lázaro Carreter pone: «menos», en vez de «menor»; «diversidad», en vez de «variedad», y «distinta», en vez de «diversa». 
Menciónanse los regímenes de los verbos que se construyen con diversas preposiciones, pues claro está, por ejemplo, que no significa lo mismo el verbo salir cuando lleva de, cuando $a$, o cuando con, según se advierte en estas frases: salir de casa; salir a canónigo, $u$ a canonjia, y salir con la empresa.l

fol. $5 \mathrm{r}$. Abunda este vocabulario en citas y remisiones, pero son todas indispensables porque, aunque los sinónimos y equivalentes van, por lo regular, colocados bajo la palabra más obvia y corriente, puede acontecer que esta palabra misma sea la que no ocurra al escritor que la busque; y en este caso discurriría mucho, y tal vez hojeando todo el Diccionario inútilmente.

Indícanse a veces como equivalentes de una dicción principal y genérica las voces. subalternas y especiales que bajo de ella se comprehenden, como cuando a los sinónimos generales perro y can se añaden las especies particulares galgo, lebrel, podenco, gozque, perdiguero, dogo, mastín, alano, etc.; o cuando a los equivalentes superior y prelado (significando cabeza de una religión) se agregan las palabras general, provincial, abad, prior, guardián, pre-

fol. 5 v. pósito, rector, prefecto, etc. A estas subdivisiones precederá por distintivo / una línea horizontal en esta forma

Muy frecuentemente se notarán omitidos los participios de muchos verbos, como amado, perseguido, etc., los diminutivos, aumentativos y superlativos, como librillo, librote, doctísimo, etc. y a veces los adverbios en mente como libremente, vilmente. La razón que ha obligado a no abultar este Prontuario con semejantes voces ha sido, como se deja inferir, la de que su formación es trivial y facilísima; suponiendo que no se escribe el Diccionario de sinónimos y equivalentes para enseñar la lengua castellana a un estranjero ni a un niño, sino para que los escritores que ya la poseen y se hallan impuestos en los precisos elementos gramaticales tengan un repertorio manual que les subministre prontamente y con abundancia términos en que elegir para ex-

fol. 6 r. presar sus ideas. Pero sin embargo del método que en esta parte se observa / por lo general en la presente obra, se citan en ocasiones algunos participios, cuando su significación aumenta, disminuye o altera en algo la de los verbos de quienes nacen, o cuando pasan a ser nombres adjetivos como afectado, instruido, descuidado, etc. Tráense también por la misma razón ciertos diminutivos y aumentativos que se diferencian notablemente de sus primitivos, v. g. mujercilla que no es como quiera un diminutivo del nombre mujer, sino una voz con que se califica a la mujer de vida escandalosa; y albardón que tampoco es un mero aumentativo de albarda, sino una especie de albarda de otra hechura particular. Del mismo modo se citan algunos superlativos de irregular formación como antiquísimo, que debiera ser antigüísimo, pues decimos antiguo y no antiquo ${ }^{56}$.

Por lo que mira a los adverbios en mente, es constante que de los sinónimos feliz, dichoso, venturoso, próspero, fausto, afortunado, derivan cual-

fol. $6 \mathrm{v}$. quiera [sic] las voces felizmente, dichosamente, / venturosamente, prosperamente, faustamente, afortunadamente. Pero cuando los adverbios no tienen esta terminación tan común y sabida, como ahora, siempre, luego, se expresarán en este Diccionario, añadiéndoles entonces los adverbios en mente que a cada uno correspondan. Así, por ejemplo, en la palabra ahora se hallarán además de los equivalentes hoy, al presente, en el día, a la hora de ésta, etc., los adverbios actualmente y presentemente.

Por el propio motivo de la facilísima formación se dejan de anotar muchos verbos de los llamados recíprocos; pues sin costar el mayor estudio, se sacarán v.g. de los equivalentes calentar, encender, acalorar, enardecer, inflamar los recíprocos calentarse, encenderse, acalorarse, enardecerse, inflamarse.

Esta última frase aparece como un añadido en el original. 
fol. $7 \mathrm{r}$. De las palabras anticuadas se ponen / aquellas que en el día pueden usar los pocos que todavía aprecian y veneran el castellano antiguo y castizo, o los que componiendo versos se ven precisados por el metro y por el consonante a dejar las voces más usuales en esta era y recurrir a las que ya sólo se conservan en los escritos de otras edades, o en fin los que escribiendo en estilo familiar y festivo pueden tomarse muchas licencias en la elección de las voces. Tales son horadar, allende, ledo, raudo, sendo, alteza por altura, y otras a este tenor. Pero se omiten bastantes vocablos ya enteramente desusados, como home por hombre, cá en lugar de porque, etc. ${ }^{57}$.

De las voces estranjeras modernamente introducidas se citan aquellas

fol. $7 \mathrm{v}$. que en algún modo son tolerables, o que contando algunos años / de antigüedad en Castilla se hallan ya connaturalizadas.

fol. $8 \mathrm{r}$. De esta especie son las dicciones: petimetre, palco, atacar por embestir y algunas más. Pero se suprimen con todo cuidado los términos introducidos muy recientemente y sin necesidad en castellano, como v. g. ascendiente por predominio, superioridad, mando, imperio o dominio que una persona tiene en otra, remarcable por notable ${ }^{58}$.

Igualmente se omiten como desconocidas en el legítimo castellano las voces andaluzas, aragonesas, catalanas, valencianas y otras. Pero, en cambio, podrán observar los lectores que contiene este Diccionario varios vocablos y frases que se echan de menos en el de la Real Academia Española, aun en el tomo primero últimamente corregido y aumentado ${ }^{59}$. Sirvan de ejemplo

fol. $8 \mathrm{v}$. / las voces afofar por ahuecar o esponjar. Acontraltado significando la calidad de voz que tira a contralto. Agarradero por asidero, y la palabra ay, tomada no por interjección, sino por nombre substantivo, como en las frases: estar en un ay, arrojar ayes, etc. ${ }^{60}$.

No parecerá inoportuno repetir aquí por último la reflexión que arriba apuntamos de paso: que se ha escrito este Diccionario para los españoles que saben la gramática castellana y la fuerza de los términos de su lengua, pues sin este previo y necesario conocimiento para el cual está expresamente destinado el Diccionario de la Academia Española, la misma abundancia de las palabras sinónimas y casi sinónimas o equivalentes que aquí se acumulan podrá ocasionar gravísimos abusos en la propiedad del estilo. Mas no ha desalentado este recelo al recopilador del Tesoro que ahora se da al público, pues

57 Después del «etc.», se lee en el original: «amistanza». En el borrador (fol. 11 v.), - había escrito Iriarte a propósito de estas palabras: «De las antiguas se ponen las que todavía pueden tener uso, particularmente en la poesía; mas no aquellas de la Conquista [de] Ultramar, etc., que no pueden ser útiles en el día».

58 En el borrador (ibíd.) se lee lo siguiente: «Aunque se señalan las voces modernas, se omiten las modernas como ascendiente, que son puros galicismos introducidos sin necesidad.» Se observará que desaparece aquí la palabra galicismo.

59 Del llamado Diccionario de Autoridades, decidieron los académicos hacer una segunda edición, de la cual sólo apareció -en 1770 - el primer tomo, coǹ dos mil doscientas voces más que en 1726: véase F. Lázaro Carreter, «Crónica del Diccionario de Autoridades (1713-1740)», Madrìd, Real Academia Española, 1972, pp. 100-101 (recogido en sus Estudios de lingüística, Barcelona, Ed. Crítica, 1980, pp. 147-148). Es de observar que Iriarte, al rechazar las voces extra-castellanas, manifiesta un criterio opuesto al de la Academia, que había incorporado deliberadamente varios elementos del léxico periférico (véase ibíd., pp. 26-30; en los citados Estudios, pp. 90-93).

60 Después del «etc.», se lee en el original, como añadido: «amarillento, aletargado», voces que efectivamente no están en la reed. del primer tomo del Diccionario de Autoridades. 
fol. 9 r. iguales inconvenientes pueden y suelen originarse del célebre / diccionario latino de voces y frases poéticas latinas que compuso en Francia el P. Vanier ${ }^{61}$, y sin embargo todos los sabios conocen la utilidad de aquella obra y la tributan los debidos elogios.

61 Alusión al famoso Dictionarium poeticum del Padre Jacques Vanière (S. J.), publicado por primera vez en Lyon en 1710 (reed. de 1722 y 1750) y del cual se hizo un Epítome (ibíd., 1717). 